\title{
Crenças, valores e representações sociais da violência ${ }^{1}$
}

MARIA STEA CROSSI PORTO*

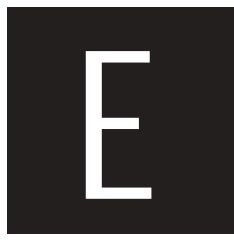

ste texto pretende explicitar a utilização que tenho feito da noção de representações sociais enquanto possibilidade de compreensão do fenômeno da violência contemporânea, assumindo ser impossível compreender esse fenômeno sem se interrogar sobre os sentidos, os valores e as crenças que estruturam e presidem a vida social, os quais são o conteúdo por excelência das representações sociais. É parte das reflexões que tenho desenvolvido sobre a possibilidade de retomar a outrora recorrente questão das crenças e dos valores, a re-inserindo no rol de dispositivos disponíveis à explicação sociológica. A questão parece re-ganhar atualidade quando se discute o papel e o lugar da subjetividade na teoria e sua relação com o também recorrente requisito da objetividade como condição para produção de conhecimento válido.

A indagação que se coloca é a de como trabalhar a categoria valor - e sua relação com crenças - sem recorrer ao meramente normativo, recurso que transforma, por vezes, a teoria em um agregado de wishful thinking.

\footnotetext{
* D outora em Sociologia. Professora do Departamento de Sociologia da Universidade de Brasília, UnB. Brasil. 1 Seminário Temático - A Constituição das Fronteiras nas Ciências Sociais: Tensão e Extensão no Campo M etodológico apresentado na Reunião Anual da AN PO CS, Caxambu, out., 2004.
} 
U ma possibilidade entre outras para enfrentar o problema seria assumir que os valores são a matéria-prima do fazer sociológico, seguindo a trilha weberiana de que a objetividade do conhecimento nas ciências sociais vincula-se ao fato de o empiricamente dado estar em permanente relação com "idéias" de valor. Sob esse prisma, poder-se-ia questionar os determinantes da ação, em suas possibilidades e limites ante à estrutura e a organização sociais, recolocando valores e crenças no interior da explicação sociológica.

A questão relativa a como implementar uma tal proposta está longe de ser simples: minha argumentação iria no sentido de pretender que a "noção" de representações sociais pode ser um caminho fértil para a apreensão dessas crenças e valores, os quais demandariam, por sua vez, serem apreendidos e analisados em sua condição de princípiosorientadores da conduta.

Convém adiantar, neste minúsculo preâmbulo, que o texto não pretende proceder a uma revisão, "Estado da Arte" ou apresentação detalhada do que venha a ser a teoria, ou a noção, de Representações Sociais. Assim, as considerações de natureza mais conceitual, presentes no decorrer do capítulo, buscam apenas situar o leitor e tornar mais clara a apropriação, se assim se pode dizer, que faço desta noção, no trabalho de pesquisa. Um outro esclarecimento introdutório é o de que parto do pressuposto da viabilidade de se avançar no conhecimento de um dado fenômeno, no caso da violência, através da análise de Representações Sociais, D esta perspectiva, tal análise apresenta-se como estratégia e caminho para a abordagem da realidade e se constitui, deste ponto de vista, em instrumento (ou estratégia) metodológico.

Como ensina Alexander (1997, p. 192),

as explicações morfológicas, materialistas e estruturais implicam geralmente métodos de observação e de demonstração estatísticas. As explicações religiosas emocionais e culturais, ao contrário, demandam mé- 
todos que privilegiem a interpretação, a introspecção e a reconstrução imaginária.

À afirmação de Alexander poder-se-ia acrescentar que isto é assim, justamente pelo fato de tais explicações articularem crenças e valores, os quais, acrescentaríamos em benefício da nossa argumentação, são o conteúdo por excelência das representações sociais.

N ascida com D urkheim nos primórdios da constituição da Sociologia como ciência, como Representações Coletivas, a noção foi re-trabalhada, re-visitada e sistematizada pela Psicologia Social, mais precisamente por Moscovici que também foi o responsável por seu re-batismo como Representações Sociais. Juntamente com M oscovici, Jodelet (2001) é, na psicologia social, a autora que, estudando representações sociais, tem insistido na necessidade que os indivíduos ressentem de se situarem no mundo, explicar esse mundo e se explicarem dentro dele, apontando, ao mesmo tempo, para o fato de as representações sociais serem a forma como os indivíduos concretizam tal necessidade. Neste sentido, ensina Jodelet (2001, p. 17),

Frente a esse mundo de objetos, pessoas acontecimentos ou idéias, não somos (apenas) automatismos, nem estamos isolados num vazio social: partilhamos esse mundo com os outros, que nos servem de apoio, às vezes de forma convergente, outras pelo conflito, para compreendê-lo, administrá-lo ou enfrentá-lo. Eis por que as representações são sociais e tão importantes na vida cotidiana... Elas circulam nos discursos, são trazidas pelas palavras e veiculadas em mensagens e imagens midiáticas, cristalizadas em condutas e em organizações materiais e espaciais.

Continuando, adverte ainda que este conhecimento, orientando condutas, tem sentido prático e contribui para criar a realidade da qual fala e à qual se refere. Embora não se vá refazer aqui a história e a trajetória deste conceito, a citação acima é relevante por explicitar e situar a importância da noção. 
A apropriação que dela aqui se faz é, em certo sentido, utilitarista: não percorre passo a passo o caminho dos que, na psicologia social se dedicaram ao tema nem privilegia a parte da teoria que se dedica aos aspectos propriamente cognitivos da formação e da constituição das representações sociais e de seus mecanismos de difusão. Além do que, não há, nessa apropriação, uma preocupação em dissecar uma dada representação, ressaltando de que modo se constituíram seu núcleo central e suas periferias. Aliás, aqui não se distingue centro e periferias. Pelo contrário, trabalhase a noção como um todo e sempre no plural, assumindo as representações sociais enquanto blocos de sentido articulados, sintonizados ou em oposição e em competição a outros blocos de sentido, compondo uma teia ou rede de significações que permite ao analista avançar no conhecimento da sociedade por ele analisada. A história deste percurso e das modificações sofridas ao longo desta trajetória já está feita pelos autores que, sobretudo, mas não exclusivamente, na psicologia social se dedicam ao tema. ${ }^{2}$

Valeria também mencionar que, dos vários enfoques a partir dos quais o fenômeno da violência tem sido abordado, aquele centrado na análise das representações não tem merecido estatuto privilegiado na Sociologia, 0 que justifica que sejam explicitadas as razões para esta escolha, as quais fundamentam-se no reconhecimento da importância teórico-metodológica do conceito como estratégia de conhecimento do social. Alguns pressupostos informam esta abordagem e resumem reflexões que foram sendo elaboradas ao longo do período dedicado à análise da violência no Distrito Federal. São pressupostos que, de uma forma ou de outra, estão presentes em reflexões teóricas e/ou análises empíricas distintas as quais busco, agora, tratar de modo mais sistematizado e ordenado.

O conhecimento via representações sociais é um tipo de conhecimento que poderia ser dito de segundo grau, não por ser menos relevante 
do que aquele obtido de "primeira mão", mas na medida em que chega-se a ele interrogando a realidade através do que se pensa sobre ela. Exemplificando, ao invés de centrar a análise nos dados brutos da violência, interroga(m)-se o(s) imaginário(s) construído(s) sobre a violência. Esta é uma característica que diz respeito à relação do pesquisador com seu objeto de pesquisa, o qual, longe de ser um dado, tem que ser construído como tal. Afirmação cujo desdobramento pressupõe o objeto do conhecimento como distinto do objeto real e que, voltando a Bourdieu, reconhece que o problema social, não sendo necessariamente um problema sociológico, precisa ser construído como tal. Tal preocupação faz sentido, mesmo quando se prioriza, como tenho buscado fazer, o empiricamente existente mais do que o normatizado institucional ou legalmente. $E$ faz mais sentido ainda quando está em questão a reflexão sobre a violência, a qual, como já afirmado acima, não é um conceito teórico, mas um fenômeno empírico.

Estes pressupostos, de caráter metodológico podem ser assim resumidos: as Representações Sociais a) "embora resultado da experiência individual, (...) são condicionadas pelo tipo de inserção social dos indivíduos que as produzem; b) expressam visões de mundo objetivando explicar e dar sentido aos fenômenos dos quais se ocupam, ao mesmo tempo em que, c) por sua condição de representação social, participam da constituição desses mesmos fenômenos; d) em decorrência do exposto em ' $b$ ', apresentamse, em sua função prática, como máximas orientadoras de conduta; e) em decorrência do exposto em ' $c$ ' pode-se admitir a existência de uma conexão de sentido (solidariedade) entre os fenômenos e suas representações sociais, que, portanto, não são nem falsas nem verdadeiras mas a matéria prima do fazer sociológico".

O que vai ser dito a seguir está, direta ou indiretamente, ligado a esses pressupostos. Inicio pelas conexões entre representações sociais e a relação indivíduo/sociedade - núcleo central da explicação sociológica para alguns, falso dilema para outros. 
A afirmação de que as representações sociais, embora resultado de experiências individuais, são condicionadas e, neste sentido, dependentes das inserções sociais dos indivíduos que as produzem, sem retomar o eterno debate em torno das relações indivíduo/sociedade, visa a situá-lo em nossa problemática. A depender do paradigma orientador da teoria, o debate em pauta ora percebe tal relação como um conflito inconciliável ora a assume a partir de uma simbiose total entre os doistermos que a constituem. D a perspectiva aqui adotada, uma forma mais profícua para pensar a questão seria admitir que indivíduo e sociedade configuram uma relação de mútua dependência, dialeticamente conflituosa em alguns contextos, relativamente harmoniosa em outros admitindo, também, e sobretudo, que o indivíduo, longe de ser um mero suporte de estruturas, tem que ser tomado em consideração em sua condição de agente ou ator, em condição de fazer algumas escolhas e tomar algumas decisões, mesmo que de modo limitado.

Com Durkeim, "o verdadeiro inventor do conceito" de representações nos dizeres de Moscovici (2001), a dialética ou tensão desta relação indivíduo/sociedade, pode ser captada, por exemplo, pela distinção entre representações individuais e representações coletivas, sendo que as primeiras, por estarem vinculadas à experiência individual, são mais variáveis e incomunicáveis: são percepções, sensações, imagens localizadas na consciência de cada indivíduo, não podem nunca se constituir em base segura para a formação dos conceitos passíveis de serem partilhados e comunicados entre os indivíduos. Já as representações coletivas, não tendo como substrato as consciências individuais são produto da consciência coletiva, mais impessoais e resistentes à mudança, portanto. (Durkheim, 1985). Diferentemente das representações sensíveis (individuais) o conceito:

está fora do tempo e do devir, está subtraído a toda essa agitação, dir-se-ia que está situado em uma região diferente do espírito, mais serena e mais calma... 
resiste à mudança... (e)... se muda não é porque seja de sua natureza mudar; é que se descobre nele alguma imperfeição; é que ele tem necessidade de ser retificado...

Além de ser relativamente imutável, o conceito é, senão universal, ao menos universalizável. "o que o torna impessoal e, portanto, apto a propiciar processos de comunicação" (D urkeim, 1985, p. 618, 619). Para efeitos da presente argumentação é importante reter dessa discussão que, em Durkheim, os conceitos, sendo representações coletivas são

comunsà um grupo social inteiro \{e\} correspondem à maneira como esse ser especial que é a sociedade pensa as coisas de sua experiência própria... mesmo quando essas representações têm o caráter geral, que Ihes é mais habitual, elas são obra da sociedade e ricas de sua experiência (Durkheim, 1985, p. 621).

Concordando-se com Moscovici (2001), pode-se aceitar que, para Durkheim, predomina uma grande homogeneidade nas representações coletivas, que em um dado momento circulam numa sociedade. Estas, sem serem eternas são bastante permanentes. 0 realce dado à homogeneidade torna-se então um componente bastante problemático da teoria, se se quer contemplar a fragmentação, a multiplicidade e a pluralidade valorativa das sociedades contemporâneas. Comentando os pressupostos metodológicos que informam a elaboração das "Regras do Método Sociológico", diz Alexander (1997, p. 192), que

Ao longo de sua carreira científica, Durkheim sempre tentou resolver o problema da relação entre o impacto aparentemente coercitivo e externo da estrutura social de uma parte, e os efeitos internos e aparentemente mais voluntários das representações simbólicas, dos sentimentos e das emoções e da ação social... ele nunca chegou a uma perspectiva satisfatória e coeren- 
te sobre a relação entre estrutura social e ação social, entre as forças materiais e culturais, entre morfologia social e representações sociais'.

Entretanto, ainda que concordando com Alexander, eu arriscaria a afirmar (e, com isto relativizaria a crítica acima citada, feita por M oscovici) que este caráter não resolvido da tensão abre espaço para considerar a função metodológica das representações sociais. 0 u seja, em sua formulação teórica, D urkheim levanta questões e abre algumas brechas nas lacunas daquilo que ficou, por assim dizer, não resolvido.

Por exemplo, ao admitir, como o faz nas Regras do M étodo Sociológico, que "a vida social é toda ela feita de representações" (D urkheim, 1971, p. XVII) e que "a idéia que fazemos das práticas coletivas, do que constituem, ou do que devem ser, representa um dos fatores do seu desenvolvimento", (D urkheim, 1971, p. XXI), Durkheim aponta para o que, nos termos dos pressupostos acima delinead os constitui o que se está chamando a solidariedade existente entre o fenômeno e sua representação. Já nas afirmações de que “...o que importa saber não é a maneira pela qual tal pensador concebe individualmente determinada instituição, mas sim a concepção que dela formula o grupo" ...(e) "que somente essa concepção é socialmente eficaz" (D urkheim, 1971, p. XXI, XXII), fica implícita a possibilidade de se fazer esta leitura metodológica da utilização da noção de representações sociais, ressaltando mais o fato do condicionamento social dos atores do que a contribuição da experiência individual, desde que se pense o grupo como uma categoria plural de análise, podendo variar as representações sociais, a depender dos grupos nos quais estão inseridos os atores sociais que as formulam.

A ressalva acima é importante, já que muitas das dificuldades com as quais D urkheim se confrontou tiveram como origem a insistência na idéia, já mencionada, da homogeneidade de conteúdo das representações coleti- 
vas, espécie de ênfase na noção de totalidade que persegue sua reflexão, sobretudo quando trata de consciência coletiva e de representações coletivas. A idéia de perseguição não é aqui uma força de expressão: seria possível admitir que a quase obsessão com a qual Durkheim reifica, por assim dizer, o social decorreria (paradoxalmente?) da percepção que teve o autor do surgimento e do crescimento do fenômeno da individualidade e de seus desdobramentos em termos da prevalência do individualismo nas sociedades modernas. Ainda assim, mesmo utilizando este termo forte que é o da obsessão, eu arriscaria a afirmar que Durkheim, diferentemente do que pretendem alguns de seus críticos e comentadores, não resolve a tensão indivíduo/sociedade através da (morte) aniquilamento do sujeito ${ }^{3}$ em favor das instituições mas, ao contrário, atento ao despertar e à preponderância do individualismo nas sociedades modernas, busca redefini-lo de modo a poder incorporá-lo à sua sociologia: por meio da mediação do social, faz do assim chamado individualismo egoísta um individualismo moral, do culto à personalidade individual, um reconhecimento da autonomia do indivíduo, mesmo insistindo, por um lado, que o objeto desse culto é o indivíduo em abstrato e não o ser humano concreto e, por outro, que esse individualismo moral é produto, resultado da vida social que antecede o indivíduo, lógica e cronologicamente.

Recorro mais uma vez a Alexander que, apesar de uma elaboração um pouco diversa, argumenta em direção próxima. Segundo esse autor, quando Durkheim, ao definir o fato social no 1 o cap. das "Regras", introduz a idéia de que as "maneiras de ser" (com a qual define o fato social) não passam de "maneiras de fazer consolidadas", ele está de fato abrindo uma vertente importante e diferente daquela centrada em explicações de natureza apenas morfológica. Isto porque tais maneiras de fazer incluem “tipos

3 Durkeim não utiliza a noção de sujeito, mas como, de um modo geral, seus críticos acusam-no de matar o sujeito, creio ser possível utilizar indivíduo e sujeito para expor minha argumentação. 
de condutas e de pensamento, maneiras de agir, de pensar, de sentir, representações e ações". Para Alexander (1997), Durkheim introduz aí uma inflexão teórica que abre espaço, na análise sociológica, para as considerações da vida interior e subjetiva dos atores e das sociedades. $\mathrm{O}$ u, poder-seia acrescentar, abre espaço para considerar as Representações Sociais, já que essa vida interior e subjetiva de que fala Alexander está informada por crenças, valores e ditados populares, conteúdos por excelência do que Durkheim nomeou como Representações Coletivas.

Não tendo como retomar aqui toda a sociologia do conhecimento de Durkheim, afirmaria que ele reconhece esta luta dos atores em sua recusa a submergirem ao peso das estruturas, quando, nas "Regras", chama a atenção para a tendência, nas sociedades modernas ao desaparecimento de pontos fixos de referência, únicos capazes de garantir a "objetividade" dosfatos sociais contra as pré-noções. $\mathrm{N}$ a falta de tais pontos, uma pluralidade conflitual de pontos de referência pretenderia vigência (Michaud, 1978). Em outras palavras, vários valores buscariam coexistir no interior de uma sociedade. $\mathrm{O}$ u, poder-se-ia dizer, representações sociais distintas poderiam surgir e pretender hegemonia, à proporção que a) a diferenciação social progredisse e os conteúdos da consciência coletiva se fossem enfraquecendo enquanto produtores de homogeneidade social; e b) a crescente autonomia individual permitisse ao ator social incorporar sua experiência individual ao agir, articulando-a aos condicionantes sociais, que - enquanto máximas orientadoras de conduta - informam esse agir.

Resumindo e, talvez com isso, localizando uma das origens das ambigüidades de Durkheim, diria que, se do ponto de vista existencial ele reconhece e admite o peso da individualidade, do ponto de vista metodológico, a explicação sociológica é, para ele, irredutível ao ator social em sua subjetividade. Em minha avaliação, é justamente por ter-se dado conta da importância dos indivíduos enquanto atores na vida social que D urkheim se apressa (conscientemente ou não) em desenvolver uma metodologia da explicação 
sociológica que "busca neutralizar" este papel. No limite, poder-se-ia falar de sujeitos agonizantes, mas não ausentes. Acho que Durkheim reconhece esta luta dos sujeitos em sua recusa a submergirem ao peso das estruturas, quando ele admite (como se mencionou aqui de modo breve) o desaparecimento de pontos fixos de referência (Durkheim, 1978).

Ainda assim, embora se possa detectar, nas brechas e lacunas teóricas, alguma semelhança com a idéia weberiana da pluralidade valorativa, este enfoque metodológico do autor afasta-o radicalmente das correntes orientadas para o individualismo metodológico, que priorizam o ator social e sua condição, como ensina Weber (1991), de único portador de sentido das máximas orientadoras das condutas que constituem a vida social.

Tais máximas podem ser resultantes da elaboração de um único indivíduo (ou de um indivíduo único, diria Weber), se portador de carisma. M as podem ser - e são na maioria das vezes - originárias de instituições sociais, como igrejas, Estado, grupos, associações, e que produzem, sob a forma de leis, convenções, usos, costumes, hábitos, os valores que consumimos e que dão sentido ao cotidiano das modernas sociedades.

A interpretação da ação deve tomar nota do fato fundamentalmente importante de que aquelas formações coletivas que fazem parte tanto do pensamento cotidiano quanto do jurídico (ou de outras disciplinas) são representações de algo que em parte existe e em parte pretende vigência, que se encontram na mente de pessoas reais (não apenas dos juízes e funcionários mas também do "público") e pelas quais se orientam suas ações. Como tais têm importância causal enorme muitas vezes até dominante para o desenrolar dasações de pessoas reais (Weber, 1991, p. 09). ${ }^{4}$ 
Implícita na formulação encontra-se, por um lado, a idéia de escolha, de seleção que, mesmo inconscientemente, informa o agir de atores reais.

As representações, de que fala Weber, constituem-se em valores, costumes ou normas jurídicas que 0 ator precisa levar em consideração ainda que para transgredi-las:

pode-se "orientar" a ação pela vigência de uma ordem não apenas cumprindo o sentido dessa ordem.... Também no caso de se "contornar" ou "violar" esse sentido pode atuar a probabilidade em algum grau de sua vigência (como norma obrigatória).... U u existem de fato interpretações diferentes do sentido da ordem, das quais - para a Sociologia - cada uma tem "vigência" na medida em que efetivamente determinas as ações (Weber, 1991, p. 20-21).

Da perspectiva weberiana, funcionam como situação, condição, ambiente, para as ações sociais podendo facilitá-las, dificultá-las e/ou inviabilizálas ou serem apenas um dado que o sujeito precisa levar em consideração no agir social. Essa citação abre espaço para a afirmação, já discutida na parte um, do caráter fragmentado do social, assim como conduz a pensar a pluralidade e a relatividade dos conteúdos valorativos que demandam do ator escolha e seleção.

Pensando em termos da violência como representação de uma ordem (Machado, mimeo, 2003) que pode ser também, algumas vezes, representação de um valor, pode- se caracterizá-la como um conteúdo a disputar hegemonia no mercado dos bens materiais e simbólicos. Compreendê-la, causalmente e em termos de seus resultados no âmbito da ação social, implica buscar os sentidos orientadores das condutas (dos atores) e compreender tais sentidos inseridos em contextos sociais, nos quais são, por exemplo, formuladas políticas públicas de enfrentamento da violência. Em alguns casos, como o da violência pela violência - dita 
despolitizada ou sem objeto - pode-se supor que \{a violência\} foi, ela mesma, erigida em valor (violência como afirmação identitária, como afirmação pela força). Já em outros, torna-se relevante investigar quais valores, crenças e sentidos estão em busca de hegemonia no contexto social, a partir do qual condutas violentas se desenvolvem como a forma mais imediata de resolução de conflitos. Exemplo de um desses valores e de seus desdobramentos em termos de prática social: a não de todo ultrapassada cultura da virilidade, muito bem expressa no ditado popular "homem que é homem não leva desaforo pra casa".

Em conformidade com a sociologia weberiana, a compreensão do social requer a compreensão das idéias de valor que perpassam o ambiente (cultura) no qual os atores interagem; nas palavras de Weber (1986, p. 87):

não existe qualquer análise científica puramente 'objetiva' da vida cultural, ou (...) - dos 'fenômenos sociais' que seja independente de determinadasperspectivas especiais e parciais, graças às quais essas manifestações possam ser, explícita ou implicitamente, consciente ou inconscientemente, selecionadas, analisadas e organizadasna exposição enquanto objeto de pesquisa.

Seleção esta condicionada à relação dos fenômenos culturais com idéias de valor. É esta significação cultural que vai permitir a um dado fenômeno se constituir como objeto de análise, resultando daí, diz o autor, que "o conhecimento da realidade cultural é sempre um conhecimento subordinado a pontos de vista especificamente particulares" (Weber, 1986, p. 97). Com todas as dificuldades que o tema comporta, Weber avança seu ponto de vista para concluir que a "objetividade do conhecimento no campo das ciências sociais depende antes do fato de o empiricamente dado estar constantemente orientado por idéias de valor que são as únicas a conferir-Ihe valor de conhecimento" (Weber, 1986, p. 126). 
Esta passagem de Weber parece sinalizar, aos moldes de um laisser passer, para a utilidade de uma abordagem metodológica centrada na análise das representações sociais cujos conteúdos nada mais são do que idéias de valor que uma determinada cultura elabora sobre os fenômenos da vida social. Neste sentido, e chamando a atenção para o objetivo (que ocupa minha pesquisa) de compreender e explicar as representações sociais da violência, formuladas por diferentes setores da sociedade brasileira, esta abordagem é um recurso (dentre outros, aqui não há pretensão de exclusividade) para avançar na compreensão dessa mesma sociedade. A questão sociológica subjacente diz respeito à presença de práticas violentas como uma forma freqüente de estruturação de relações sociais ou, vista sob um outro ângulo, de resolução de conflitos.

O privilégio concedido a esta abordagem teórico-metodológica busca descartar definições abstratas; ao fazê-lo, remete a uma certa relatividade do conceito, a qual tem a ver com a multiplicidade de valores orientadores de conduta e com o fato de que representações não são independentes do campo social no qual são construídas. Assim, o que os atores sociais nomeiam como violência varia segundo as representações que estes se fazem do fenômeno. Varia igualmente segundo a natureza da sociedade na qual o fenômeno é definido. Sob este aspecto, quanto mais uma sociedade é unilateral quanto a suas normas e valores, tanto menos aparece o caráter relativo do conceito e se tem a ilusão de objetividade construída por uma suposta unidade de pontos de vista. Sociedades mais plurais convivem com uma multiplicidade normativa, coexistindo lado a lado, ou disputando hegemonia. Afirmação que faz com que a questão da inserção social dos atores readquira relevância: as representações sociais são passíveis de distinções, em função dos múltiplos pertencimentos socioeconômicos e culturais nos quais os indivíduos e/ou grupos de indivíduos se inserem. Um outro exemplo poderia vir em suporte da argumentação: a desigualdade 
socioeconômica, por um lado, o caráter hierárquico em termos sociais e valorativos, por outro, pode fazer das diferenças sociaissinônimo de inferioridade e transformar o diferente em alvo potencial e/ou real de discriminação.

Considerando os fenômenos da violência, a perspectiva analítica centrada nas Representações Sociais permite captar os sentidos que os atores (protagonistas ou vítimas da violência) atribuem às suas representações e às suas práticas, sem secundarizar o sistema (ambiente, contexto, situação, estruturas) no qual esses atores agem e onde ações violentas são praticadas. Privilegia a subjetividade das representações sabendo, no entanto, que elas só se constroem em relação a um dado contexto ou ambiente objetivamente dado. $\mathrm{O}$ u seja, subjetividade e objetividade são assumidas, tanto uma quanto a outra como componentes fundamentais desta forma de relação social.

Interrogado o componente objetividade, violência seria o que os números e as estatísticas assinalam como tal, fazendo ressaltar o caráter "inegável" da realidade do fenômeno. Por outro lado, pensada de um ponto de vista subjetivo, violência precisaria considerar, igualmente, o que diferentes indivíduos e sociedades reputam (representam) como violência. Representação que poderia, em última instância, interferir na própria realidade da violência, reforçando a necessidade de uma estratégia de análise que se interrogue sobre as relações objetividade/subjetividade enquanto componentes que participam da definição do fenômeno da violência e interferem nas práticas e nas representações que diferentes grupos elaboram de tais práticas.

Aprofundando um pouco mais esta linha de raciocínio, é possível supor que existam, por um lado, contextos (objetivos) mais ou menosfavoráveis ao desenvolvimento da violência, e que por outro, o que é representado como violência (dimensão subjetiva) "participe" igualmente da realidade da violência. Se determinados contextos favorecem o desenvolvimento de manifestações de violência, esta, uma vez posta em ação, manifesta aos 
atores o poder de sua utilização. Neste sentido, uma violência que inicialmente se constitui a partir de um contexto propício produz, ou pode produzir, a violência como lógica de intervenção. 0 que está em questão não é algo como o círculo vicioso da violência mas o fato, já ressaltado, de serem objetividade e subjetividade dois elementos interagindo solidariamente na constituição do fenômeno. Assim, definir algo ou alguém como violento implica captar as relações entre objetividade e subjetividade da violência, estratégia que o enfoque das rep resentações sociais parece possibilitar.

Pensar a violência a partir destes parâmetros ou abordagens demanda necessariamente abrir mão de julgamentos normativos ou valorativos, pois o que está em questão não é o legal ou normativamente correto mas o efetivamente vigente. Com isto, não se está tendendo a um relativismo exacerbado, a partir do qual todos os valores se equivaleriam. Para dar um exemplo, a pretensão à legitimidade não é necessariamente (embora não se exclua esta possibilidade) sinônimo de legitimidade. Ainda que eventualmente possa sê-lo para o segmento que a reivindica. $\mathrm{O}$ u, em outros termos, aqui vale a distinção weberiana (perseguida, mas nem sempre seguida pelo próprio Weber) entre o político e o cientista (Weber, 1974). Do ponto de vista existencial, o sociólogo, em sua condição de cidadão, partilha um elenco de valorese dirige, através deles, sua conduta. Como cientista, dedica-se a compreender o elenco de valores presentes na sociedade analisada para, a partir daí, avançar seu conhecimento sobre essa sociedade.

Assim, e correndo o risco da repetição, eu diria que, para a análise sociológica, torna-se relevante para os propósitos explicativos refletir sobre a ordem empiricamente vigente, na medida em que esta, tanto quanto, ou até mesmo mais do que a ordem legal, pode ser reveladora de contextos societários e dos valores neles predominantes.

A partir desta mesma vertente, caberia ainda considerar uma outra característica do fenômeno, ou outro de seus elementos constitutivos, de alguma forma já mencionada ao longo do texto, a saber, a oposição entre a 
relatividade de que seus conteúdos se revestem (ou são passíveis de se revestir) e a pretensão a uma definição abrangente e universal.

Do ponto de vista teórico, ressaltar o aspecto relativo do fenômeno não é sinônimo de assumir um relativismo puro, a partir do qual tudo se equivale, nem é sinônimo de adesão ao credo relativista, cuja exacerbação leva ao irracionalismo que, no limite, inviabiliza a atividade científica. Do ponto de vista empírico, a ênfase posta na cultura e nas especificidades próprias a toda e qualquer sociedade aponta ao olhar sociológico a relatividade valorativa presente nas distintas culturas (e no interior de cada uma delas) a qual implica, necessariamente, distintas representações da violência, cabendo ao sociólogo tomá-las como objeto de análise, caso tenha pretensões à elaboração de uma sociologia ou teoria da violência.

Aqui se situa, talvez, um dos elementos mais complexos da questão da definição da violência: não há uma definição em abstrato, que se "aplique" a qualquer sociedade Por outro lado, o relativismo não leva a lugar nenhum. U ma forma possível de se buscar sair do impasse seria considerar que o limite para o relativismo seria a integridade, física e moral da pessoa. Desta forma, toda vez que tal integridade fosse atingida poder-se-ia assumir que se está em presença de um ato violento. É claro que aí também não se está, de todo, isento de ambigüidades, pois cabem interpretações sobre o que seja, por exemplo, integridade moral e sobre os critérios para tal classificação.

Pensando na relação objetivo/subjetivo já referida acima, seria viável admitir-se, pelo menos como uma hipótese operacional, que se poderia falar de violência sempre que a alteridade fosse desconsiderada, "esquecida", "desconhecida", "negada". Em outras palavras, sempre que o outro fosse desconsiderado como sujeito e, em função disto, tratado como objeto, inviabilizando, em última análise, a interação social, fosse ela de natureza consensual ou conflituosa. 
Argumentando a partir de reflexões propostas por M ichaud (1978 e 1996) W ieviorka afirma não ser realista se ater a uma ou outra das polaridades em questão:

a violência é objetiva ou subjetiva? O bjetiva, ela deveria poder ser definida em termos que transcendem as perspectivas particulares e adquire uma validade universal. Subjetiva, ela não passa de um ponto de vista, necessariamente relativo, daquele que a descreve ou sofre (...) a violência jamais é redutível à imagem da pura objetividade simplesmente porque o que é concebido ou percebido como "violento" varia no tempo e no espaço (...) Mas, por outro lado, a violência não pode ser redutível aos afetos, às representações e às normas que dela propõem tal grupo ou tal sociedade (...) a percepção de violências reconhecidas como tal oscila constantemente entre o excesso e a falta, entre a tendência à dramatização e à amplificação e a propensão à banalização e à indiferença (W ieviorka, 1999, p. 08).

Levando ao que seriam, para ele, os dois impasses que ameaçam a apreensão da violência, a saber, o universalismo e o relativismo, a citação abaixo, ainda que um pouco longa, conclui de modo particularmente felize pertinente 0 argumento do autor:

$N$ ão seria realista nem opor radicalmente o objetivo e o subjetivo - ou, se se prefere, o universal e o relativo - nem escolher um ao invés do outro, ou um contra o outro. De modo semelhante ao que se passa em relação a todo fato social: é necessário admitir que a violência, sobretudo em sua expressões físicas, até mesmo homicidas, pode ser objeto de uma definição que tende à objetividade, mas é necessário reconhecer, ao mesmo tempo que o que se assume como real é produto de processos, individuais e coletivos, através dos 
quais categorizamos, selecionamos, hierarquizamos, entendemos ou ignoramos o que constitui a "realidade" (W ieviorka, 1999, p. 09).

U m outro componente a ser considerado na análise centrada em representações sociais é o fato de estas expressarem visões de mundo, explicando e atribuindo sentido aos fenômenos dos quais se ocupam. Trata-se de compreender as relações entre representações sociais e a compreensão do mundo por parte dos agentes socais: tais relações supõem solidariedade entre o fenômeno e sua representação, nos termos propostos por M ichaud (1996, p. 41), para quem

existe atualmente uma conexão substantiva entre a contribuição real de situações e eventos no mundo e o saber que sobre eles temos ou acreditamos ter. A solidariedade entre evento e representação do evento é total... os vínculos entre realidade e representação da realidade são impossíveis de serem desfeitos.

Da mesma forma como justificam e orientam as práticas dos atores sociais acerca de um fenômeno, assim também, a depender de como são apropriadas pelas instâncias institucionais, as representações sociais podem justificar e orientar políticas públicas.

U m exemplo banal ilustra meu argumento: 0 medo e a sensação de insegurança são muito maior nos condomínios fechados das megalópoles brasileiras do que na maioria das periferias destas mesmas cidades. Tais sentimentos fazem com que os moradores dos primeiros se tranquem e se protejam utilizando-se de toda a gama de implementos que a moderna tecnologia produziu para a área da segurança e, freqüentemente, nada têm a ver com a realidade concreta da violência nestes espaços. Entretanto essa sensação de insegurança "cria" uma demanda por aumento de segurança. Q uando aliada a outras representações, tais como as de impunidade, de ineficiência ou ineficácia do sistema público de segurança, induz à utiliza- 
ção do já referido aparato de segurança em benefício da defesa de interesses particulares, privados, em detrimento do coletivo. Este descrédito que leva a uma lógica do "salve-se quem puder e como puder" é compatível com outra lógica que informa este tipo de raciocínio, a do "fazer justiça com as próprias mãos", levando cidadãos a se armarem e a se prepararem para pôr em prática a clássica afirmação da ciência política acerca da guerra de todos contra todos, ou a recorrerem ao Estado, reivindicando aumento de repressão, como saída para conter a destruição e combater a ineficácia real ou representada - do aparato público de justiça. 0 descrédito nestas instituições provedoras de justiça e de segurança acaba sendo, igualmente, o mote para alavancar a indústria bélica, acionada na guerra urbana e responsável pela produção de um gigantesco aparato tecnológico de "proteção", que, na prática, coloca o cidadão que dele se utiliza como o agente de sua própria segurança.

Resumindo, a representação acerca de um fenômeno é parte constitutiva desse mesmo fenômeno, "criando-o", em certo sentido. Assim, no processo de investigação de um crime, a definição do "suspeito" é resultado, além dos chamados "dados objetivos", de uma construção social para a qual as representações sociais contribuem de modo significativo. Um outro exemplo, a impunidade, real ou representada, pode, igualmente, alimentar práticas violentas.

Desta perspectiva de análise, entender por que a sociedade produz certas representações sobre um fenômeno ou sobre algumas de suas instituições revela-se mais pertinente do que preocupar-se apenas em sentenciar sobre a condição de falsa ou de verdadeira de uma dada representação. O u seja, a violência são os fatos da violência, exemplo, um homicídio, um corpo no chão, o sangue na calçada, mas são também as representações sociais dessa violência. Além disso, representações sociais não são racionais ou irracionais embora respondam, certamente, por uma lógica e uma racionalidade que as constituem em objeto do conhecimento, a serem, 
portanto, submetidas ao crivo da ciência. Racionalidade de uma natureza totalmente distinta daquela que o conhecimento da ciência proporciona. Para o analista do social, se é pertinente buscar as relações entre o fenômeno e suas representações, não é por considerar que as últimas sejam sinônimo do real e sim, por assumi-las como um dado de realidade que precisa ser submetido à análise como condição de produção de um conhecimento pertinente.

A pesquisa centrada na análise de representações sociais busca ressaltar a contribuição substantiva que crenças, valores, ditados popularese ideologias, tomados em sua condição de representações sociais, aportam ao conhecimento do social, descartando, pois, sua definição como algo irracional, ausente de vínculos lógicos com o real. À condição, evidentemente, de assumi-las pelo que de fato são: substrato material, sinal externo, vida cristalizada (Durkheim, 1978). Por sua vez, a definição mesma de violência não é indiferente ao campo social que a elabora: o fato de uma dada sociedade se pensar, ou não, em termos da categoria violência depende dos valores aí vigentes.

Considerar a profunda e estreita interdependência entre variáveis de natureza objetiva e subjetiva seria, nos termos weberianos, incorporar a análise das idéias de valor no processo de conhecimento e na explicação sociológica, praticando a vigilância epistemológica que impede a incorporação dos próprios valores nos resultados da pesquisa. O u, significaria, valendo-se da terminologia durkheimiana, tomar os valores e a moral como objeto de investigação, praticando uma sociologia da moral e não uma sociologia moral.

A reflexão pretendida buscou enfatizar a importância das representações sociais na perspectiva de que permitem centrar o foco da compreensão nos indivíduos, sem desconhecer que eles não pairam no ar: movem-se e movem suas práticas sociais em contextos específicos. 
Aqui também vale a afirmação, segundo a qual, ação social e representação social são fenômenos solidários: as subjetividades presentes nas representações da violência interferem, direta ou indiretamente, nos processos de organização das ações e relações sociais, ou seja, nos espaços nos quais o social se produz e se reproduz como espaço de interação.

\section{Referências}

ALVES-M AZZOTTI, A. J. Representações Sociais: aspectos teóricos e aplicações à Educação. Em Aberto, Brasília, ano 14, n.61, jan./mar. 1994. p. 60-78.

ACKERM AN N, W. DULO NG, R. et JEU DI, H .-P (orgs). Imaginaires de I'Insécurité. Paris: Librarie des Meridiens, 1983.

BLÁZQ U EZ, G. Antropologia Social, Rituaise Representações. In: CARDO SO, C. F. e M ALERBA, J. (O rg.). Representações: Contribuição a um debate interdisciplinar. Campinas: Ed. Papirus, 2000.

BO N ARDI, C. et RO USSIAU, N. Les Représentations Sociales. Paris: Ed. Dunod, 1999.

FARR, R. M. Les Représentations Sociales. In: M O SCO VICl, S. (O rg.). Psychologie Sociale. Paris: Presses U niversitaires de France, 1984.

FARR, R. M . Representações Sociais: a teoria e sua história. In: JO VCHELO VITCH, S. e GUARESCHI, P. (O rg). O pus cit. 1994.

JO DELET, D. Représentations Sociales: un domaine en expansion. In: JO D ELET, D. (O rg.). Les Représentations Sociales. Paris: Presses U niversitaires de France, 1989.

JO DELET, D. Représentation Sociale: phénomènes, concept et théorie. In: MOSCOVICI, S. O pus cit. 1984.

MALERBA, J. Conexões entre Elias e Bourdieu. In: CARD OSO e M ALERBA.(O rg.). opus cit. 2000.

MALERBA, J. As representações numa abordagem transdisciplinar: ainda um problema indócil porém mais bem equacionado. In: CARDO SO e MALERBA (O rg.). opus cit. 2000. 
MINAYO, M. C. de S. O conceito de representações sociais dentro da sociologia clássica, in: JO VCHELO VITCH, S.e GU ARESCHI, P. (O rg.). opus cit. 1994.

MOSCOVICl, S. The phenomenon of social representations. In: FARR, R. M. e MOSCOVICl, S. (ed.). Social Representations. Cambridge e Paris: Cambridge U niversity Press e Maison des Sciences de I'Homme, 1984.

MOSCO VICl, S. A melhor forma de provar um pudim ainda é comendo-o. IIa Conference Internationale sur les représentations sociales. Rio de Janeiro. 1994.

M OSCO VICl, S. Des Représentations Collectives aux Représentations Sociales: éléments pour une histoire. In: JO DELET, opus cit. 1989.

M OSCOVICI, S. Prefácio. In: JO VCHELO VITCH, S e GUARESCHI, P.(O rg.). Textos em Representações Sociais. Petrópolis: Ed. Vozes, 1994.

O RFALI, B. Les Représentations Sociales: um Concept Essentiel et une Théorie fondamentale en Sciences Humaines et Sociales. L'Année Sociologique, 50, no 1, p 235-254. 2000.

SÁ, C. P. de. Sur les relations entre Représentations Sociales, pratiques SocioCulturelles et Comportement. In: Textes sur lês Représentations Sociales (10215573), Vol. 3 (1), 1-138. 1994.

SÁ, C. P. de. A construção do objeto de pesquisa em representações sociais. Rio de Janeiro: Ed. UERJ, 1998.

SILVA, H. R. da. A história como a 'Representação do Passado' : A N ova Abordagem da Historiografia Francesa. In: CARD O SO E M ALERBA, opus cit. 2000.

VALA, J. Sobre as representações sociais - para uma epistemologia do senso comum. Cadernos de Ciências Sociais, Lisboa, (19). 


\section{Resumo}

0 texto explicita a utilização que se faz da noção de representações sociais enquanto possibilidade de compreensão do fenômeno da violência contemporânea, assumindo, para tanto, a necessidade de se interrogar sobre os sentidos, os valores e as crenças que estruturam e presidem a vida social, que são o conteúdo por excelência das representações sociais. Discute a possibilidade de retomar a outrora recorrente questão das crenças e dos valores enquanto parte do rol de dispositivos disponíveis à explicação sociológica. Finalmente busca refletir sobre a relação subjetividade/objetividade no contexto teórico de produção de conhecimento válido.

Palavras-chave: crenças, representações sociais, violência.

Recebido: $28 / 12 / 2005$

Aceite final: 01/02/06 


\section{Beliefs, values, and social representations of violence}

\section{Maria Stela Grossi Porto}

The text describes the use of the notion of social representation as a possibility to understand the phenomenon of contemporary violence, therefore interrogating about meanings, values, and beliefs that structure and preside over social life, which are the content of social representations par excellence. It discusses the possibility to resume the debate on the once recurrent issue of beliefs and values as included in the range of devices available for the sociological explanation. Finally, it seeks to reflect upon the subjectiveness/objectiveness relationship within the theoretical context for production of valid knowledge.

Key words: beliefs, social representations, violence 